\title{
Predictors of chronic prescription opioid use after orthopedic surgery: derivation of a clinical prediction rule.
}

\author{
Daniel I Rhon ${ }^{1,2,3^{*}}$ (D, Suzanne J Snodgrass ${ }^{3}$, Joshua A Cleland ${ }^{4}$, Charles D Sissel ${ }^{5}$ and Chad E Cook $^{6}$
}

\begin{abstract}
Background: Prescription opioid use at high doses or over extended periods of time is associated with adverse outcomes, including dependency and abuse. The aim of this study was to identify mediating variables that predict chronic opioid use, defined as three or more prescriptions after orthopedic surgery.

Methods: Individuals were ages between 18 and 50 years and undergoing arthroscopic hip surgery between 2004 and 2013. Two categories of chronic opioid use were calculated based on individuals (1) having three or more unique opioid prescriptions within 2 years and (2) still receiving opioid prescriptions $>1$ year after surgery. Univariate elationships were identified for each predictor variable, then significant variables $(P>0.15)$ were entered into a multivariate logistic regression model to identify the most parsimonious group of predictor variables for each chronic opioid use classification. Likelihood ratios were derived from the most robust groups of variables.

Results: There were 1642 participants (mean age 32.5 years, SD 8.2, 54.1\% male). Nine predictor variables met the criteria after bivariate analysis for potential inclusion in each multivariate model. Eight variables:

socioeconomic status (from enlisted rank family), prior use of opioid medication, prior use of non-opioid pain medication, high health-seeking behavior before surgery, a preoperative diagnosis of insomnia, mental health disorder, or substance abuse were all predictive of chronic opioid use in the final model (seven variables for three or more opioid prescriptions; four variables for opioid use still at 1 year; all<0.05). Post-test probability of having three or more opioid prescriptions was $93.7 \%$ if five of seven variables were present, and the probability of still using opioids after 1 year was $69.6 \%$ if three of four variables were present.

Conclusion: A combination of variables significantly predicted chronic opioid use in this cohort. Most of these variables were mediators, indicating that modifying them may be feasible, and the potential focus of interventions to decrease the risk of chronic opioid use, or at minimum better inform opioid prescribing decisions. This clinical prediction rule needs further validation.
\end{abstract}

Keywords: Prescription opioids, Opioids, Chronic opioid use, Hip surgery, Postoperative care

\section{Background}

Opioid prescriptions for managing non-cancer-related pain have been on the rise in the US, reaching epidemic proportions (Kolodny et al. 2015). This is problematic as the number of deaths from opioid overdose are also rising, increasing by $27.6 \%$ from 2015 to 2016 , and 34.5\%

\footnotetext{
*Correspondence: daniel_rhon@baylor.edu

${ }^{1}$ Center for the Intrepid, Brooke Army Medical Center, 3551 Roger Brooke Drive, JBSA Fort Sam, Houston, TX 78234, USA

${ }^{2}$ Doctoral Program in Physical Therapy, Baylor University, San Antonio, TX, USA

Full list of author information is available at the end of the article
}

from 2016 to 2017 in the US (Vivolo-Kantor et al. 2018). Between 21 and $43 \%$ of individuals that take prescriptions opioids for chronic musculoskeletal pain will misuse them or develop substance abuse disorders (Ives et al. 2006; Martell et al. 2007; Vowles et al. 2015).

Multiple clinical practice guidelines address opioid prescription for chronic non-cancer pain indicating that opioids should not be considered the first line of treatment (Dowell et al. 2016; Nuckols et al. 2014). However, there is less focused on opioid use for acute pain, such as after traumatic injuries or surgical procedures. For

(c) The Author(s). 2018 Open Access This article is distributed under the terms of the Creative Commons Attribution 4.0 International License (http://creativecommons.org/licenses/by/4.0/), which permits unrestricted use, distribution, and 
the most part, the latter has been warranted and accepted as standard clinical practice for pain management (Hegmann et al. 2014; Macintyre et al. 2014). However, this practice still merits caution as there is concern some patients may become chronic users after being treated for acute pain (Frieden and Houry 2016; Kaplovitch et al. 2015). As many as $13 \%$ of opioid-naive individual undergoing orthopedic surgery may go on to chronic opioid use (Johnson et al. 2016). Orthopedic surgeons are the third highest prescribers of opioid pain medication (Morris and Mir 2015), as they must help their patients adequately manage acute pain during the postoperative period. Dosage patterns of opioid prescriptions have been shown to influence chronic opioid use after orthopedic surgery (Cook et al. 2017; Kim et al. 2017), but there may be other influential variables that help predict chronic use.

For these reasons, identification of risk factors that predict misuse of prescription opioids has been the target of much research (Cochran et al. 2014; Kaye et al. 2017; Skala et al. 2013). However, the majority of research has focused on abuse (such as misuse, addiction, and aberrant behavior) and less on chronic use (proper use over a longer period of time). Chronic opioid use is associated with numerous potential adverse effects (Baldini et al. 2012), many of which develop over time (Els et al. 2017). Information that may help predict whether a patient is at higher risk of becoming a chronic opioid user is vital for informing optimal clinical decision-making, such as identifying which comorbidities associated with chronic use and targeting them for earlier interventions.

The purpose of this study was to identify patient variables that predicted chronic prescription opioid use in the 2 years following arthroscopic hip surgery.

\section{Methods}

\section{Study design}

The study was an observational cohort of patients within the Military Health System (MHS) that underwent arthroscopic hip surgery between 30 June, 2004, and 1 July, 2013.

\section{Setting}

Data were derived from the MHS Data Repository (MDR), which captures and tracks all medical visits for all beneficiaries of the Department of Defense (DoD). This includes retired, active military, and service family members. The MDR is the centralized data repository that captures, archives, validates, integrates, and distributes Defense Health Agency corporate health care data worldwide. Any medical visit, in a military or civilian setting, where the DoD insurance plan TRICARE is the payer (covering 100\% of armed services personnel and their dependents) is captured in the MDR.

\section{Participants}

To keep the population homogenous, the intent was to identify adult patients undergoing hip arthroscopy specifically for femoroacetabular impingement (FAI) syndrome. FAI syndrome is a musculoskeletal disorder of the hip more common in younger adults and often treated with surgical correction of joint morphology (Amanatullah et al. 2015; Fayad et al. 2013). In fact, it is the most common reason for arthroscopic hip surgery in younger, active adults in civilian as well as military populations (Dutton et al. 2016), with a fivefold increase in the US between 2005 and 2013 (Kremers et al. 2017) Therefore, subjects under 18 or over 50 years of age were excluded, leaving those that best represents the age range for symptomatic FAI syndrome (Clohisy et al. 2013). Because FAI syndrome does not have a diagnosis code established by the International Classification of Diseases (ICD-9), we identified surgical procedures used to treat this condition, in order to make the cohort more homogenous. Any subject with a recorded encounter in the system that specifically included an arthroscopic hip procedure, identified by Current Procedural Terminology (CPT) codes of 29914, 29915, 29916, and 29862, was included in the cohort. All subjects with potential confounding diagnosis codes present prior to the surgery, which could otherwise rationalize the need for arthroscopic hip surgery, were excluded (hip osteoarthritis, hip avascular necrosis, hip or pelvis fracture, or neoplasm). Patients with any additional hip surgeries (revisions, contralateral side, or hip arthroplasty) during the 2-year follow-up period were also excluded. All patients that were not eligible beneficiaries in the DHA health insurance plan for 12 months before and 24 months after surgery were also excluded. Finally, only subjects that received opioid prescriptions after surgery were included in the analyses (Fig. 1). Additional details of the extraction for cohort have been published and available (Rhon et al. 2018).

\section{Reporting guidelines}

The Transparent Reporting of multivariate prediction model for Individual Prognosis Or Diagnosis (TRIPOD) statement for developmental prediction models was used to guide the reporting of this study (Collins et al. 2015). Ethical approval for the study was granted by the Brooke Army Medical Center Institutional Review Board.

\section{Data sources/measurement}

Data from MDR includes person-level data for all outpatient and inpatient medical visits, in both military and civilian hospitals. Within the US, the data from the MDR reflects a single-payer system as compared to the more common private-insurance-based system. It also includes any prescriptions filled, to include total unique 


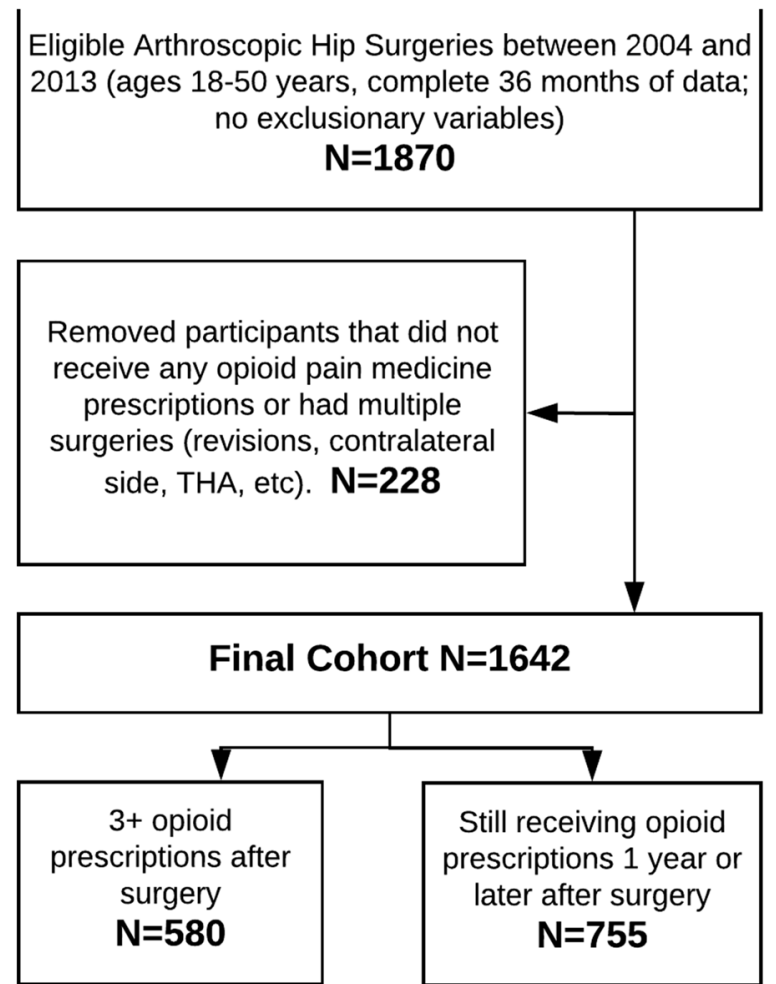

Fig. 1 Cohort extraction

prescriptions and days' supply of medication for each prescription. The data were abstracted and aggregated by a senior healthcare analyst working for the Army Medical Command with over 10 years of experience and who routinely aggregates data of this nature. De-identified data were provided to the investigators in raw form (one line for each unique medical visit) and also in an aggregated file at the single-person level, with a total sum of each care variable for each unique subject. The aggregate data was validated against the raw data by a different investigator (other than the healthcare analyst), and if any questions arose or further clarification was needed, then the issue was brought to the attention of the senior analyst for consensus.

\section{Study variables \\ Descriptive variables}

Patient characteristics included mean age, sex, total healthcare visits (including those unrelated to surgery), and total healthcare costs (including those unrelated to surgery), sex, active duty status, socioeconomic status (categorized as officer or enlisted), and location of surgery (military treatment facility (MTF) or civilian hospital).

\section{Outcome variables}

Opioid prescriptions were identified by using the American Hospital Formulary Service (AHFS) therapeutic class codes (280808 and 280812) found in the Pharmacy Data Transaction Service (PDTS) section of MDR. The prescription date and type are provided at the person level. Because opioids prescribed at the time of surgery are likely associated with the initial dose provided to manage immediate postoperative pain, occurrences of opioid prescriptions within the immediate perioperative window (0-2 days) were excluded from the frequency counts. Current clinical practice guidelines include prescription of opioid-based medication to manage acute postsurgical pain, and therefore, we expected most patients to have at least one prescription immediately after surgery. However, we were more interested in subsequent prescriptions and management patterns beyond this perioperative prescription. There were two outcomes used in this study. The first was defined by unique individuals with three or more unique opioid prescriptions within a 24-month timeframe (designated as three or more opioids). The second was defined as unique individuals who received any opioid prescriptions that took place at least 1 year or more after surgery (designated as "1 year+" cohort). The first outcome allowed us to assess frequency and has been used to define chronic opioid use in previous studies (DeVries et al. 2014; Yang et al. 2015; Zarling et al. 2016). The second outcome allowed for a more temporal assessment over time. We did not assess perioperative prescription dosing variables at baseline, as the goal was to capture clinical practice delivered in a pragmatic manner, allowing for the individualized variations required in dosing for immediate postoperative pain management.

\section{Predictor variables}

In recognition that various comorbidities can influence general healthcare utilization, a number of comorbidities were identified based on a medical visit with a corresponding ICD-9 code. A recent systematic review identified nine predictive models for determining opioid abuse, and the majority were based on diagnosis codes (ICD-9) (Alzeer et al. 2018). Specific details for how these variables were extracted and their relevance to prognosis in individuals with musculoskeletal outcomes have been published (Rhon et al. 2018). Seventeen variables were identified as potential predictors. Demographic predictors included age, sex, location of surgery, and socioeconomic status. Military rank was used to define socioeconomic status, as a proxy measure of education, income, and cultural role. Few enlisted personnel (7.6\%, 2015 data) have a Bachelor's degree or higher (Office of the Deputy Assistant Secretary of Defense for Military Community and Family Policy (ODASD (MC\&FP)) 2015) compared to nearly $100 \%$ of military officers, who usually commence military service with a Bachelor's degree or are expected to have it within the 
first few years of service. Incomes are higher for higher ranking military officers, and though it is possible that their spouses have high incomes increasing the family's socioeconomic status, spouse income is unlikely to influence socioeconomic status more than rank. Even so, spousal income would likely favor higher ranking personnel because less enlisted personnel (51\%) are married compared to military officers (69.6\%) (Office of the Deputy Assistant Secretary of Defense for Military Community and Family Policy (ODASD (MC\&FP)) 2015). Finally, military-assigned housing is often geographically segregated by rank reflecting the military culture, e.g., lower ranked enlisted personnel are typically housed in smaller homes in one geographic area, with senior officers in much larger homes in a different geographic area.

Medical history predictors included preoperative diagnosis of insomnia, mental health disorder, substance abuse, or presence of chronic pain. Behavioral-based predictors included preoperative opioid use (Sing et al. 2016; Zarling et al. 2016; Zywiel et al. 2011), preoperative non-opioid pain medication use, and high health-seeking behavior [defined by dividing the total health visits into quartiles and dichotomizing the groups into low healthcare-seeking (quartile 1 through 3) and high healthcare-seeking (quartile 4)]. Care-oriented predictors included three or more visits of rehabilitation for the hip, occurrence of a hip infection, surgical procedures of femoroplasty (cam lesion), acetabuloplasty (pincer lesion), and arthroscopic repair of labrum. Specific diagnosis and procedure codes used for each category in this cohort have been published (Rhon et al. 2018).

\section{Statistical approach}

Our methodology involves cluster predictive analyses, a form of multivariate predictive modeling that appropriately identifies patterns associated with the predicted variable. Cluster predictive analyses, sometimes referred to as clinical prediction rules, are especially beneficial when the model incorporates standard patient-level or clinical-level factors that are readily available in most clinician-patient encounters.

All analyses were performed using SPSS version 24.0 (IBM Corp. Armonk, NY, USA). Descriptive statistics representing raw data for the categories of three or more prescriptions of opioids and $<3$ prescriptions of opioids were calculated, including means, standard deviations, and frequencies and distributions, where appropriate. Bivariate assessments were provided to determine differences across groups.

Bivariate relationships were analyzed with 17 individual logistic regression analyses for both outcome variables [(1) three or more unique prescriptions and (2) still receiving prescriptions at 1 year or greater]. For each analysis, odds ratios and 95\% confidence intervals were captured, as well as $p$ values and Nagelkerke $\mathrm{R}^{2}$ measures. A Nagelkerke $R^{2}$ is a goodness of fit measure that reflects the explanatory strength of the predictor within a model (Bewick et al. 2005). Values closer to 1.0 suggest strong explanation whereas values near zero suggest only weak explanation.

The univariate findings from the bivariate logistic regression analyses for both outcome measures (three or more prescriptions of opioids and opioid prescription of 1 year or greater) that exhibited $p$ values of $<0.05$ were retained for the multivariate regression analysis. To assure appropriate modeling, a multicollinearity assessment for each of the retained variables was performed using correlation matrices. A correlational finding of $r>$ 0.7 between independent variables was used to assess the potential of multicollinearity (Shen and Gao 2008). Since no variables exhibited a correlation greater than 0.4, all variables were retained for both multivariate models. Because there is some overlap with variables, we chose to adjust only for military status (active duty service member or other, to include family member or retired service member) and socioeconomic status (four categories: junior or senior enlisted and junior or senior officer), as these are best supported in the literature (Bennett et al. 2013; Edlund et al. 2014) and the cohort was relatively homogenous already with no influence on dependent variables found through independent analysis of other factors.

For the multivariate analyses, a backward stepwise logistic regression was used. For both multivariate models, a $p$ value of $\leq 0.05$ was considered significant for the bivariate analyses, whereas $95 \%$ confidence intervals that did not cross 1 were considered significant for all likelihood ratio analyses. Variables retained by the regression model were used to create conditions, a unique feature of a clinical prediction rule (CPR). Depending on the number of variables retained in the stepwise regression, findings were inputted into $2 \times 2$ contingency tables that involved the conditions of 1 of $X, 2$ of $X, 3$ of $X$, and so on. For each condition, sensitivity, specificity, and likelihood ratios and 95\% CIs were calculated. In each condition, post-test probability measures were calculated using pretest probabilities within the sample. For the first multivariate model, the pre-test probability of three or more opioids prescriptions was $35.5 \%$ whereas the pre-test probability of an opioid prescription of 1 year or longer was $53.1 \%$. We calculated post-test probability of a negative and positive finding using a post-test probability calculator.

\section{Results}

There were 1642 individuals that met the criteria and were included in analysis. There were notable differences 
among those who received three or more opioid prescriptions and those who did not, including age, sex socioeconomic status, and healthcare utilization. A greater rate of individuals in the three or more opioid prescriptions utilized prescription opioids prior to surgery (50.7\% vs $34.7 \%$ ). Higher medical costs and visits (both general and specifically hip related) were present in the three or more opioid prescription group as well (Table 1). The mean total days' supply of opioids was much higher in the three or more opioid prescription group (125.7 days vs 5.7 days).

Bivariate logistic regression analyses identified eight variables that were significantly associated with receiving three or more opioid prescriptions in a 24-month period (Table 2). Female sex, history of preoperative opioid prescriptions, having received non-opioid-based pain medication prescriptions prior to surgery, high health-seeking behavior, and a preoperative diagnosis of insomnia, chronic pain, substance abuse disorder, or mental health disorder were all associated with higher odds of receiving three or more opioid prescriptions within a 24-month period after surgery.

Bivariate logistic regression analyses identified five variables that were significantly associated with ongoing opioid prescriptions beyond 1 year (Table 3). Female sex, lower socioeconomic status, high health-seeking behavior, and a preoperative diagnosis of a substance abuse or mental health disorder were associated with higher odds of receiving a new prescription for opioids 1 year or later after surgery.

Multivariate analyses identified seven variables that were associated with receiving three or more opioid prescriptions 24 months after surgery (Table 4). Preoperative prescription opioid use (OR 2.62; 95\% CI $2.02,3.39$ ), preoperative non-opioid pain medication prescription (OR 1.37; 95\% CI 1.03, 1.81), high health-seeking behavior (OR 7.23; 95\% CI 4.94, 10.54), female sex (OR 1.28; 95\% CI 1.02, 1.61), preoperative insomnia (OR 2.09; 95\% CI 1.42, 3.09), mental health disorder (OR 2.24; 95\% CI 1.61, 3.09), and substance abuse disorder diagnoses (OR 1.45; 95\% CI 1.07, 1.98) all contributed to higher odds of receiving three or more opioids in a 24-month period. The Nagelkerke $R^{2}$ was 0.19 .

Multivariate analyses for individuals receiving opioids beyond 1 year postoperatively in a 24-month period identified four variables associated with this outcome (Table 5). Female sex (OR 1.62; 95\% CI 1.30, 2.01), preoperative substance abuse disorder (OR 1.50; 95\% CI 1.11, 2.04), and high health-seeking behavior (OR 4.39; $95 \%$ CI 2.97, 6.47) were associated with higher odds of receiving an opioid prescription at 1 year or later. Being an officer or in an officer family was associated with lower odds of having an opioid prescription 1 year or more after surgery (OR 0.59; 95\% CI 0.46, 0.77). The Nagelkerke $R^{2}$ was 0.25 .

Table 6 outlines the sensitivity, specificity, and positive and negative likelihood ratios of the clustered models for each outcome variable. In addition, a post-test probability of meeting the selected conditions (e.g., 1 of $X, 2$ of $X$ ) is provided based on the prevalence of those with three or more opioid prescriptions or those who received opioid prescriptions within the 24 months beyond 1-year post-surgery. As expected, the positive likelihood ratio increases when greater numbers of positive findings in selected conditions are met (e.g., 5 of $X, 6$ of $X$ ) with decreasing sensitivity of the models. Post-test probabilities of having three or more opioid prescriptions start at $39.9 \%$ with at least one variable and rise to $100.0 \%$ if at least six or seven of the seven variables are present. Post-test probabilities of having still receiving an opioid prescription 1 year or later after surgery start at 53.3\% with at least one variable and rise to $77.7 \%$ if all four variables are present (Table 6).

\section{Discussion}

The aim of this study was to derive a CPR to identify patients who might be more likely to become chronic users of prescription opioids after orthopedic hip surgery. While other studies have utilized prescription data to define chronic opioid use (Fritz et al. 2018; Sites et al. 2018; Thackeray et al. 2017), this study is the first to develop a clinical prediction rule based on opioid prescription patterns validated from pharmacy data in claims records. The focus of our investigation was to better understand variables that may improve clinical decision-making related to managing patients that are taking opioids after surgery and at the same time generate hypotheses for future trials. Several clinically relevant patient-level and healthcare services utilization variables were identified and include use of non-opioid pain medication prior to surgery, younger age, female, lower socioeconomic status (military rank, representing education and household income), high health-seeking behavior, and presence of substance abuse, insomnia, or mental health disorders prior to surgery. The variables in this CPR were able to identify individuals that received three or more opioid prescriptions in a 2-year period, as well as individuals still receiving new opioid prescriptions at least 1 year after surgery. This CPR can help clinicians identify patients that may be at higher risk become chronic opioid users after orthopedic surgery.

Prior opioid use is one of the strongest predictors of chronic opioid use and poor outcomes (i.e., longer hospital stays, higher rates of pain management referrals, higher rates of postoperative complications) after orthopedic surgery (Chan et al. 2017; Sing et al. 2016), and while it was significant in predicting three or more opioid prescriptions, it was not significant in predicting 
Table 1 Descriptive statistics $(N, \%)$ for the total sample and those with and without three or more opioid prescriptions ( $p$ value compares these two groups)

\begin{tabular}{|c|c|c|c|c|c|c|c|}
\hline Variable & $\begin{array}{l}\text { Total } \\
\text { sample } \\
(N=1642)\end{array}$ & $\begin{array}{l}\text { Individuals with } 3 \\
\text { or more prescriptions } \\
\text { for opioids } \\
(N=580)\end{array}$ & $\begin{array}{l}\text { Individuals with } \\
\text { less than } 3 \text { or } \\
\text { no prescriptions } \\
\text { for opioids } \\
(N=1062)\end{array}$ & $P$ value & $\begin{array}{l}\text { Individuals still receiving } \\
\text { opioid prescriptions after } \\
1 \text { year }(N=755)\end{array}$ & $\begin{array}{l}\text { Individuals not } \\
\text { receiving opioid } \\
\text { prescriptions after } \\
1 \text { year }(N=887)\end{array}$ & $P$ value \\
\hline Age (SD) & $32.45(8.18)$ & $31.37(7.74)$ & $32.85(8.39)$ & $<0.01^{*}$ & $32.9(8.5)$ & $31.9(7.8)$ & $<0.01^{*}$ \\
\hline Sex-female & $754(45.9)$ & $298(51.4)$ & $456(42.9)$ & $<0.01^{*}$ & $388(51.4)$ & $366(41.3)$ & $<0.01^{*}$ \\
\hline $\begin{array}{l}\text { Active duty family } \\
\text { (service or family } \\
\text { member }\end{array}$ & $1108(67.5)$ & $387(66.7)$ & $721(67.9)$ & 0.63 & $523(69.3)$ & $585(66.0)$ & 0.15 \\
\hline \multicolumn{8}{|l|}{ Service } \\
\hline Army & $783(47.7)$ & $290(50.0)$ & $435(41.0)$ & $<0.01^{*}$ & $351(46.5)$ & $374(42.3)$ & 0.29 \\
\hline Coast Guard & $29(1.8)$ & $7(1.2)$ & $22(2.1)$ & & $11(1.5)$ & $18(2.0)$ & \\
\hline Air Force & $448(27.3)$ & $134(23.1)$ & $280(26.4)$ & & $187(24.8)$ & $227(25.6)$ & \\
\hline Marine Corps & $214(13.0)$ & $65(11.2)$ & $129(12.1)$ & & $83(11.0)$ & $111(12.5)$ & \\
\hline Navy & $288(17.5)$ & $84(14.5)$ & 187 (17.6) & & $122(16.2)$ & 149 (16.8) & \\
\hline Other & $8(0.5)$ & 0 & $7(0.5)$ & & 1 & $6(0.5)$ & \\
\hline Socioeconomic status & & & & $<0.01^{*}$ & & & $<0.01^{*}$ \\
\hline Junior enlisted & $390(23.8)$ & $182(31.4)$ & 208 (19.6) & & $202(26.8)$ & $188(21.2)$ & \\
\hline Senior enlisted & $842(51.3)$ & $305(52.6)$ & $537(50.7)$ & & $418(55.4)$ & $424(47.8)$ & \\
\hline Junior officer & $200(12.2)$ & $54(9.3)$ & $146(13.7)$ & & $71(9.4)$ & $129(14.5)$ & \\
\hline Senior officer & $192(11.7)$ & $39(6.7)$ & $153(14.4)$ & & $64(8.5)$ & $128(14.4)$ & \\
\hline Unknown & $18(1.1)$ & 0 & $18(1.7)$ & & 0 & $18(2.0)$ & \\
\hline $\begin{array}{l}\text { Military hospital [versus } \\
\text { civilian] }\end{array}$ & $837(51.0)$ & $293(50.5)$ & $544(51.2)$ & 0.78 & $373(49.4)$ & $464(52.3)$ & 0.24 \\
\hline \multicolumn{8}{|c|}{ Total medical care within 2 years after surgery (SD) } \\
\hline $\begin{array}{l}\text { Mean medical } \\
\text { visits }\end{array}$ & $80.94(67.13)$ & $119.58(86.50)$ & $59.83(40.31)$ & $<0.01^{*}$ & $105.1(80.0)$ & $60.4(44.6)$ & $<0.01^{*}$ \\
\hline $\begin{array}{l}\text { Mean medical } \\
\text { costs }\end{array}$ & $\$ 25,380(\$ 24,604)$ & $\$ 36,199(\$ 32,372)$ & $\$ 19,471(\$ 16,292)$ & $<0.01^{*}$ & $\$ 32,140(\$ 28,778)$ & $\$ 19,626(\$ 18,555)$ & $<0.01^{*}$ \\
\hline $\begin{array}{l}\text { Mean hip-related } \\
\text { medical visits }\end{array}$ & $24.41(22.31)$ & $32.42(28.31)$ & $20.04(17.56)$ & $<0.01^{*}$ & $29.0(25.7)$ & $20.5(18.1)$ & $<0.01 *$ \\
\hline $\begin{array}{l}\text { Mean hip-related } \\
\text { medical costs }\end{array}$ & $\$ 13,185(\$ 14,187)$ & $\$ 15,665(\$ 16,119)$ & $\$ 11,831(\$ 12,819)$ & $<0.01^{*}$ & $\$ 14,546(\$ 15,639)$ & $\$ 12,027(\$ 12,717)$ & $<0.01^{*}$ \\
\hline $\begin{array}{l}\text { Individuals with a } \\
\text { prescription prior to } \\
\text { surgery }\end{array}$ & $662(40.3)$ & $294(50.7)$ & $368(34.7)$ & $<0.01^{*}$ & $399(52.8)$ & $416(46.9)$ & $0.02^{*}$ \\
\hline \multicolumn{8}{|c|}{ Opioid prescription use after (SD) } \\
\hline $\begin{array}{l}\text { Mean unique } \\
\text { prescriptions }\end{array}$ & $5.0(9.1)$ & $10.3(12.8)$ & $1.5(0.9)$ & $<0.01^{*}$ & $8.4(12.1)$ & $1.6(18.1)$ & $<0.01^{*}$ \\
\hline $\begin{array}{l}\text { Median unique } \\
\text { prescriptions }\end{array}$ & 2.0 & 6.0 & 1.0 & $<0.01^{*}$ & 5.0 & 1.0 & $<0.01^{*}$ \\
\hline $\begin{array}{l}\text { Mean total days' } \\
\text { supply }\end{array}$ & $43.0(137.1)$ & $93.7(208.2)$ & $10.1(12.2)$ & $<0.01^{*}$ & $76.3(189.8)$ & $10.3(18.1)$ & $<0.01^{*}$ \\
\hline $\begin{array}{l}\text { Median total days' } \\
\text { supply }\end{array}$ & 10.0 & 35.0 & 7.0 & $<0.01^{*}$ & 23.0 & 5.0 & $<0.01^{*}$ \\
\hline
\end{tabular}

$N(\%)$ unless otherwise indicated

SD standard deviation, MTF military treatment facility, Network non-military medical facility, ${ }^{*}$ Significant $P<0.05$ 
Table 2 Univariate relationships between predictor variables and having three or more opioid prescriptions in the 24-month period after hip surgery, adjusted for socioeconomic and active duty status

\begin{tabular}{|c|c|c|c|}
\hline Variable & Odds ratio $(95 \% \mathrm{Cl})$ & $P$ value & Nagelkerke $\mathrm{R}^{2}$ \\
\hline Age & $1.01(0.99,1.02)$ & 0.44 & 0.05 \\
\hline Preoperative use of prescription opioids & $1.81(1.46,2.23)$ & $<0.01^{*}$ & 0.07 \\
\hline Socioeconomic status (enlisted rank) & $1.12(0.72,1.73)$ & 0.62 & 0.05 \\
\hline Sex (female) & $1.37(1.12,1.69)$ & $<0.01^{*}$ & 0.06 \\
\hline MTF location for surgery (vs network) & $1.07(0.87,1.32)$ & 0.49 & 0.05 \\
\hline Insomnia preoperatively & $2.56(1.79,3.66)$ & $<0.01^{*}$ & 0.07 \\
\hline Mental health disorder preoperatively & $1.95(1.51,2.51)$ & $<0.01^{*}$ & 0.07 \\
\hline Substance abuse preoperatively & $1.68(1.27,2.23)$ & $<0.07^{*}$ & 0.06 \\
\hline Chronic pain diagnosis preoperatively & $1.53(1.08,2.15)$ & $0.01^{*}$ & 0.05 \\
\hline Non-opioid-based pain medication prescription preoperatively & $1.68(1.30,2.17)$ & $<0.01^{*}$ & 0.06 \\
\hline Health-seeking behavior preoperatively & $8.38(5.80,12.11)$ & $<0.01^{*}$ & 0.17 \\
\hline At least $3+$ visits of hip-related physical therapy preoperatively (based on median) & $1.04(0.84,1.28)$ & 0.71 & 0.005 \\
\hline Occurrence of hip infection after & $0.50(0.70,3.61)$ & 0.49 & 0.05 \\
\hline Femoroplasty (cam lesion) & $0.94(0.80,1.09)$ & 0.41 & 0.05 \\
\hline Acetabuloplasty (pincer lesion) & $1.01(0.82,1.23)$ & 0.96 & 0.05 \\
\hline Labral repair & $0.93(0.79,1.09)$ & 0.38 & 0.05 \\
\hline
\end{tabular}

MTF military treatment facility, Network non-military medical facility, ${ }^{*}$ Significant $\mathrm{P}<0.05$

which individuals were still receiving opioid prescriptions beyond 1 year in our study. It is possible that prior opioid use is related to higher numbers of unique prescriptions, but ones that occur in a shorter period of time. In addition, the presence of a substance abuse disorder diagnoses prior to surgery did predict use beyond
1 year. A diagnosis documented in a medical record may indicate a more substantial dependency problem than the utilization of opioid prescriptions alone. Interestingly, non-opioid pain medication use (most often non-steroidal anti-inflammatory drugs-NSAIDs) before surgery was a significant predictor of chronic opioid use.

Table 3 Univariate relationships between predictor variables and still receiving an opioid prescription 1 year or more after hip surgery, adjusted for socioeconomic and active duty status

\begin{tabular}{llll}
\hline Variable & Odds ratio $(95 \% \mathrm{Cl})$ & $P$ value & Nagelkerke $\mathrm{R}^{2}$ \\
\hline Age & $0.99(0.98,1.01)$ & 0.88 & 0.02 \\
Preoperative use of prescription opioids & $1.19(0.96,1.47)$ & 0.11 & 0.02 \\
Socioeconomic status (enlisted rank) & $0.56(0.35,0.89)$ & $0.02^{*}$ & 0.02 \\
Sex (female) & $1.54(1.24,1.91)$ & $<.01^{*}$ & 0.03 \\
MTF location for surgery (vs network) & $1.13(0.92,1.40$ & 0.23 & 0.02 \\
Insomnia preoperatively & $1.23(0.85,1.78)$ & 0.27 & 0.02 \\
Mental health disorder preoperatively & $1.45(1.11,1.89)$ & $<0.01^{*}$ & 0.02 \\
Substance abuse preoperatively & $1.9291 .48,2.49)$ & $<0.01^{*}$ & 0.04 \\
Chronic pain diagnosis preoperatively & $1.41(0.98,2.03)$ & 0.06 & 0.02 \\
Non-opioid-based pain medication prescription preoperatively & $0.97(0.75,1.27)$ & 0.83 & 0.02 \\
Health-seeking behavior preoperatively & $4.48(3.05,6.59)$ & $<0.01^{*}$ & 0.08 \\
At least 3+ visits of hip-related physical therapy preoperatively (based on median) & $1.15(0.93,1.42)$ & 0.19 & 0.02 \\
Occurrence of infection after & $1.09(0.15,7.87)$ & 0.93 & 0.02 \\
Femoroplasty (cam lesion) & $9.95(0.81,1.10)$ & 0.50 & 0.02 \\
Acetabuloplasty (pincer lesion) & $0.98(0.81,1.21)$ & 0.90 & 0.02 \\
Labral repair & $0.90(0.77,1.06)$ & & 0.02 \\
\hline
\end{tabular}

MTF military treatment facility, Network non-military medical facility, ${ }^{*}$ Significant $P<0.05$ 
Table 4 Results of multivariate analysis demonstrating variables that predict having three or more opioid prescriptions in the 24month period after hip surgery, adjusted for socioeconomic and active duty status

\begin{tabular}{lll}
\hline Variable & Odds ratio $(95 \% \mathrm{Cl})$ & $P$ value \\
\hline Preoperative use of prescription opioids & $2.62(2.02,3.39)$ & $<0.01^{*}$ \\
Insomnia, preoperatively & $2.09(1.42,3.09)$ & $<0.01^{*}$ \\
High health-seeking behavior preoperatively & $7.23(4.94,10.54)$ & $<0.01^{*}$ \\
Substance abuse preoperatively & $1.45(1.07,1.98)$ & $0.02^{*}$ \\
Non-opioid-based pain medication prescription preoperatively & $1.37(1.03,1.81)$ & $0.03^{*}$ \\
Mental health disorder diagnosis preoperatively & $2.24(1.61,3.09)$ & $<0.01^{*}$ \\
Sex (female) & $1.28(1.02,1.61)$ & $0.03^{*}$ \\
\hline
\end{tabular}

*Significant $P<0.05$

It may be that for chronic and/or persistent symptoms, patients that had already tried non-opioid-based pain medications before surgery were more likely to make the jump to stronger pain medication after surgery. It is unclear if medical providers considered the preoperative utilization of non-opioid analgesics as satisfying an initial tier of pain management and were more willing to prescribe stronger medication post-surgically. Studies show that prescription patterns for stronger pain medication are dependent on prior history of non-opioid analgesic medication (Muller et al. 2012; Ndlovu et al. 2014).

Females may be at greater risk for chronic opioid use after surgery (Johnson et al. 2016; Walid et al. 2007) and more prone to opioid dependency in general (Back et al. 2011; Unger et al. 2010). Females on higher doses are much less likely to taper down to a lower dose than males (Weimer et al. 2016). While the proportion of females is much lower than males in the military, the rate of injuries is much higher in females (Kodesh et al. 2015; Kucera et al. 2016; Roy et al. 2015). A much higher percent of females in the military are undergoing arthroscopic hip surgery and are much less likely to remain in the military after surgery compared to males (Thomas et al. 2017). In 2015, females made up $16.8 \%$ of the military force (Office of the Deputy Assistant Secretary of Defense for Military Community and Family Policy (ODASD (MC\&FP)) 2015), but they represent 30\% or greater of patients in published hip arthroscopy cohorts in the military (Byrd et al. 2016; Dutton et al. 2016;

Table 5 Results of multivariate analysis demonstrating variables that predict still receiving an opioid prescription 1 year or more after hip surgery, adjusted for socioeconomic and active duty status

\begin{tabular}{lll}
\hline Variable & Odds ratio $(95 \% \mathrm{Cl})$ & $P$ value \\
\hline Socioeconomic status (officer rank) & $0.59(0.46,0.77)$ & $<0.01{ }^{*}$ \\
Sex (female) & $1.62(1.30,2.01)$ & $<0.01{ }^{*}$ \\
Substance abuse preoperatively & $1.50(1.11,2.04)$ & $<0.01{ }^{*}$ \\
Health-seeking behavior preoperatively & $4.39(2.97,6.47)$ & $<0.01{ }^{*}$ \\
\hline *Significant $P<0.05$ & &
\end{tabular}

Thomas et al. 2017). As female sex was as a predictor in our final model, this may be a subset of the population that merits further research when it comes to postoperative pain management.

Socioeconomic status has also been shown to be a risk factor for chronic opioid use (Schoenfeld et al. 2017). Enlisted (Bennett et al. 2013) and younger service members (Ramirez et al. 2017) are much more likely to misuse opioids than officers and older service members. This was corroborated in our findings as well, which identified belonging to an enlisted family was a significant predictor of receiving a new opioid prescription 1 year or later after surgery. These variables should be considered by providers in the Military Health System when crafting pain medication management strategies after surgery.

Orthopedic surgeries are some of the most traumatic, often involving reconstruction of the bone, tendon, and muscle. As such, orthopedic surgeons often prescribe opioids to help manage acute postoperative pain (Morris and Mir 2015). In many cases, this may serve as an initial introduction to opioid medication for a patient. Understanding which variables from a patient's profile or medical history might lead to a higher risk of chronic opioid use has been identified as a critical need for orthopedic surgeons (Kee et al. 2016). In high-risk cases, perhaps alternate pain management strategies (i.e., non-opioid analgesics) (Martinez et al. 2017; White 2002) could be employed earlier, especially as some of these may be just as effective as opioid-based pain medications, and in some cases superior (Martinez et al. 2017).

Finally, complication rates could potentially influence chronic opioid use. Studies have linked chronic opioid use with higher surgery-related complication rates within the first 90 days following surgery (Sing et al. 2016). Higher levels of opioid prescriptions are associated with greater gastrointestinal complications and longer hospital stays in patients undergoing joint arthroplasty (Mörwald et al. 2018). In our cohort, we excluded anyone with additional hip surgeries 
Table 6 Clinical prediction rule for each of the two chronic opioid utilization definitions

\begin{tabular}{|c|c|c|c|c|c|}
\hline & $\begin{array}{l}\text { Sensitivity }(95 \% \\
\text { CI) }\end{array}$ & $\begin{array}{l}\text { Specificity }(95 \% \\
\text { CI) }\end{array}$ & $\begin{array}{l}\text { Positive Likelihood } \\
\text { Ratio }(95 \% \mathrm{CI})\end{array}$ & $\begin{array}{c}\text { Negative } \\
\text { Likelihood } \\
\text { Ratio }(95 \% \text { CI) }\end{array}$ & $\begin{array}{c}\text { Post-test } \\
\text { Probability } \\
\text { When Variables } \\
\text { are Present }\end{array}$ \\
\hline \multicolumn{6}{|c|}{3 or more opioid prescriptions (Pre-test Probability $=35.3 \%$ ) } \\
\hline 1 or more of 7 variables present & $93.3(91.1,95.0)$ & $23.4(22.3,24.4)$ & $1.22(1.17,1.26)$ & $0.29(0.20,0.39)$ & $39.9 \%$ \\
\hline 2 or more of 7 variables present & $69.3(66.1,72.4)$ & $61.5(59.7,63.2)$ & $1.80(1.64,1.97)$ & $0.49(43.7,56.8)$ & $49.5 \%$ \\
\hline 3 or more of 7 variables present & $38.6(35.9,41.2)$ & $88.8(87.3,90.2)$ & $3.44(2.82,4.22)$ & $0.69(0.65,0.73)$ & $65.2 \%$ \\
\hline 4 or more of 7 variables present & $11.4(9.7,12.9)$ & $97.0(96.1,97.8)$ & $3.78(2.46,5.83)$ & $0.91(0.89,0.94)$ & $67.3 \%$ \\
\hline 5 or more of 7 variables present & $2.6(1.9,2.7)$ & $99.9(99.5,100)$ & $27.46(3.86,557.85)$ & $0.97(0.97,0.98)$ & $93.7 \%$ \\
\hline 6 or more of 7 variables present & $1.0(<1.0,1.0)$ & $100.0(99.7,100.0)$ & $\operatorname{Inf}(1.58, \operatorname{Inf})$ & $0.99(0.99,0.99)$ & $\sim 100 \%$ \\
\hline \multicolumn{6}{|c|}{ Still receiving opioid prescriptions 1 or more years after surgery (Pre-test Probability $=53.1 \%$ ) } \\
\hline 1 or more of 4 variables present & $90.5(88.9,92.0)$ & $10.6(8.9,12.3)$ & $1.01(0.97,1.05)$ & $0.89(0.64,1.24)$ & 53.3 \\
\hline 2 or more of 4 variables present & $59.6(57.1,62.1)$ & $49.6(46.7,52.3)$ & $1.18(1.07,1.30)$ & $0.81(0.72,0.92)$ & 57.2 \\
\hline 3 of 4 variables present & $18.1(16.4,19.7)$ & $91.0(89.1,92.8)$ & $2.02(1.51,2.72)$ & $0.89(0.87,0.94)$ & 69.6 \\
\hline 4 or more of 4 variables present & $1.9(1.2,2.2)$ & $99.4(98.7,99.8)$ & $3.09(0.96,11.09)$ & $0.98(0.98,1.0)$ & 77.7 \\
\hline
\end{tabular}

Variables from tables 4 and 5; Green indicates optimal rule cutoff where post-test probability is $60 \%$ or higher.

Variables from Tables 4 and 5; green indicates optimal rule cutoff where post-test probability is $60 \%$ or higher

(revisions, contralateral surgery, joint arthroplasty), and we accounted for infection, which is one of the most common complications. Therefore, it is more likely that our findings were not affected by these factors. Hip arthroscopy is typically an ambulatory surgical procedure (e.g., same day surgery), so hospital stay would not be a factor in most cases. However, this variable, in addition to any other functional measures (e.g., time to return to walk, time to return to work, time to return to independent activities of daily living) were not available for this study.

\section{Limitations and future research}

It should be noted observational data was used, and therefore, causality cannot be implied. Further, we acknowledge that the results of any observational research rely heavily on the interpretation of the researchers and can be influenced by confounders beyond statistical adjustment. Claims data is limited by the accuracy to which it is entered into the electronic medical records. The opioid utilization data was based on prescriptions, and it is not possible to confirm that patients actually utilized their full prescriptions. However, while this may be the case for those with only one prescription, it is not likely for those that had multiple prescriptions as they would have likely completed one before requesting more. We also do not know the specific reason patients used opioids in a long term as they could have been prescribed for other reasons. Self-report variables were lacking, but would have provided valuable insight (Goesling et al. 2016). Currently, no consensus on a definition for chronic opioid use exists, and several definitions for chronic opioid use have been proposed. Our model is likely to vary based on the definition, as was shown in the two models presented in this study. The stark difference in days' supply between both the three or more or less than three opioid prescriptions (mean 93.7 vs 10.1 days) and in those still using opioids after 1 year compared to less than 1 year (mean 76.3 vs 10.3 days) indicates that our definition is likely a good proxy for chronic use. There may also be other variables with greater predictive validity, to include self-report measures, complications, and surgical procedures, that were not captured in the current study but may improve prediction algorithms. It was not possible to accurately determine the reasons for the opioid prescriptions, so it is possible that prescriptions were filled for other diagnoses. However, even with a diagnosis linked to the prescription, it would be unknown if the opioids were also acting on the hip pain because of its systemic effects. Finally, this was a specific cohort in a military setting undergoing a surgery to the hip. It is unknown if these findings could be generalized to other populations and for other conditions or body regions. Future prospective studies are needed to better identify relevant variables associated with risk of chronic opioid use after orthopedic surgery.

\section{Conclusion}

In summary, patient variables and medical history may prove informative for understanding the risk of chronic prescription opioid use after surgery. The use of pain medication prior to surgery, younger age, female, lower socioeconomic status (education and household income), high health-seeking behavior, and presence of substance abuse, insomnia, or mental health disorders prior to surgery were all significant in predicting chronic opioid use after surgery. While the presence of a single variable may be helpful, a combination of variables may have greater predictive value for determining the likelihood of chronic opioid use after surgery. As with any initial derivation of a clinical prediction rule, these results need further independent validation in other settings to determine if predictors are consistent. 


\section{Abbreviations}

AHFS: American Hospital Formulary Service; CPR: Clinical Prediction Rule; CPT: Current Procedural Terminology; DHA: Defense Health Agency; FAl: Femoroacetabular Impingement; ICD: International Classification of Diseases; MDR: Military Health System Data Repository; NSAID: Non-steroida anti-inflammatory drug; OR: Odds ratio; PDTS: Pharmacy Data Transaction Service; SD: Standard deviation; SPSS: Statistical Package for Social Sciences; US: United States

\section{Acknowledgements}

We would like to thank Dr. Katie Dry and Dr. Rachel Mayhew for their help in organizing the data from the MDR for analyses.

\section{Funding}

Funding was provided through an internal grant by the US Defense Health Agency. They played no part in the study question, design, or analyses performed.

\section{Disclaimer}

The view(s) expressed herein are those of the author(s) and do not reflect the official policy or position of Brooke Army Medical Center, the U.S. Army Medical Department, the U.S. Army Office of the Surgeon General, the Department of the Army, the Department of the Air Force, Department of Defense, or the U.S. Government.

\section{Author's contributions}

DR and CC derived the idea and concept for the study. DR received grant funding. CS abstracted and coded the data variables. DR, CC, and CS performed the analysis. SS and JC assisted with interpretation of results, writing, and all revisions of the mansucript. All authors read and approved the final manuscript.

\section{Ethics approval and consent to participate}

Ethics approval was provided by the US Army Central Health Command Institutional Review Board. No consent was required based on the nature of this study.

\section{Consent for publication}

Not applicable

\section{Competing interests}

All authors declare they have no competing interests.

\section{Publisher's Note}

Springer Nature remains neutral with regard to jurisdictional claims in published maps and institutional affiliations.

\section{Author details}

'Center for the Intrepid, Brooke Army Medical Center, 3551 Roger Brooke Drive, JBSA Fort Sam, Houston, TX 78234, USA. ${ }^{2}$ Doctoral Program in Physical Therapy, Baylor University, San Antonio, TX, USA. ${ }^{3}$ School of Health Sciences, Faculty of Health and Medicine, The University of Newcastle, University Drive, Callaghan, NSW, Australia. ${ }^{4}$ Department of Physical Therapy, Franklin Pierce University, Manchester, NH, USA. ${ }^{5}$ Program Analysis and Evaluation Division, US Army Medical Command, Joint Base San Antonio - Fort Sam Houston, San Antonio, TX 78234, USA. ${ }^{6}$ Division of Physical Therapy, Department of Orthopedics, Duke University, Duke MSK, Duke Clinical Research Institute, Durham, NC, USA.

Received: 9 June 2018 Accepted: 24 September 2018 Published online: 22 November 2018

\section{References}

Alzeer AH, Jones J, Bair MJ. Review of factors, methods, and outcome definition in designing opioid abuse predictive models. Pain Med. 2018;19(5):997-1009.

Amanatullah DF, Antkowiak T, Pillay K, Patel J, Refaat M, Toupadakis CA, et al. Femoroacetabular impingement: current concepts in diagnosis and treatment. Orthopedics. 2015;38(3):185-99.

Back SE, Payne RL, Wahlquist AH, Carter RE, Stroud Z, Haynes L, et al. Comparative profiles of men and women with opioid dependence: results from a national multisite effectiveness trial. Am J Drug Alcohol Abuse. 2011 Sep;37(5):313-23.
Baldini A, Von Korff M, Lin EHB. A review of potential adverse effects of longterm opioid therapy: a practitioner's guide. Prim Care Companion CNS Disord. 2012;14(3). https://www.psychiatrist.com/PCC/article/Pages/2012/ v14n03/11m01326.aspx.

Bennett AS, Elliott L, Golub A. Opioid and other substance misuse, overdose risk, and the potential for prevention among a sample of OEF/OIF veterans in New York City. Subst Use Misuse. 2013;48(10):894-907.

Bewick V, Cheek L, Ball J. Statistics review 14: logistic regression. Crit Care. 2005; 9(1):112-8

Byrd JWT, Jones KS, Schmitz LMR, Doner GP. Hip arthroscopy in the warrior athlete: 2 to 10 year outcomes. J Hip Preserv Surg. 2016;3(1):68-71.

Chan FJ, Schwartz AM, Wong J, Chen C, Tiwari B, Kim SJ. Use of chronic methadone before total knee arthroplasty. J Arthroplast. 2017;32(7):2105-7.

Clohisy JC, Baca G, Beaulé PE, Kim Y-J, Larson CM, Millis MB, et al. Descriptive epidemiology of femoroacetabular impingement: a North American cohort of patients undergoing surgery. Am J Sports Med. 2013;41(6):1348-56.

Cochran BN, Flentje A, Heck NC, Van Den Bos J, Perlman D, Torres J, et al. Factors predicting development of opioid use disorders among individuals who receive an initial opioid prescription: mathematical modeling using a database of commercially-insured individuals. Drug Alcohol Depend. 2014; 138:202-8.

Collins GS, Reitsma JB, Altman DG, Moons KGM. Transparent Reporting of a multivariable prediction model for Individual Prognosis or Diagnosis (TRIPOD): the TRIPOD statement. Ann Intern Med. 2015;162(1):55-63.

Cook CE, Rhon DI, Lewis BD, George SZ. Post-operative opioid pain management patterns for patients who receive hip surgery. Subst Abuse Treat Prev Policy. 2017;12(1):14

DeVries A, Koch T, Wall E, Getchius T, Chi W, Rosenberg A. Opioid use among adolescent patients treated for headache. J Adolesc Health. 2014, 55(1):128-33.

Dowell D, Haegerich TM, Chou R. CDC guideline for prescribing opioids for chronic pain--United States, 2016. JAMA. 2016:315(15):1624-45.

Dutton JR, Kusnezov NA, Lanzi JT, Garcia EJ, Pallis MP. The success of hip arthroscopy in an active duty population. Arthroscopy. 2016;32(11):2251-8.

Edlund MJ, Austen MA, Sullivan MD, Martin BC, Williams JS, Fortney JC, et al. Patterns of opioid use for chronic noncancer pain in the Veterans Health Administration from 2009 to 2011. Pain. 2014;155(11):2337-43.

Els C, Jackson TD, Kunyk D, Lappi VG, Sonnenberg B, Hagtvedt R, et al. Adverse events associated with medium- and long-term use of opioids for chronic non-cancer pain: an overview of Cochrane Reviews. Cochrane Database Syst Rev. 2017;10:CD012509.

Fayad TE, Khan MA, Haddad FS. Femoroacetabular impingement: an arthroscopic solution. Bone Joint J. 2013;95-B(11 Suppl A):26-30.

Frieden TR, Houry D. Reducing the risks of relief--the CDC Opioid-Prescribing Guideline. N Engl J Med. 2016;374(16):1501-4.

Fritz JM, King JB, McAdams-Marx C. Associations between early care decisions and the risk for long-term opioid use for patients with low back pain with a new physician consultation and initiation of opioid therapy. Clin J Pain. 2018; 34(6):552-8.

Goesling J, Moser SE, Zaidi B, Hassett AL, Hilliard P, Hallstrom B, et al. Trends and predictors of opioid use after total knee and total hip arthroplasty. Pain. 2016;157(6):1259-65.

Hegmann KT, Weiss MS, Bowden K, Branco F, DuBrueler K, Els C, et al. ACOEM practice guidelines: opioids for treatment of acute, subacute, chronic, and postoperative pain. J Occup Environ Med. 2014:56(12):e143-59.

Ives TJ, Chelminski PR, Hammett-Stabler CA, Malone RM, Perhac JS, Potisek NM, et al. Predictors of opioid misuse in patients with chronic pain: a prospective cohort study. BMC health Serv Res. 2006;6(1):46.

Johnson SP, Chung KC, Zhong L, Shauver MJ, Engelsbe MJ, Brummett C, et al. Risk of prolonged opioid use among opioid-naïve patients following common hand surgery procedures. J Hand Surg Am. 2016:41(10):947-57.e3.

Kaplovitch E, Gomes T, Camacho X, Dhalla IA, Mamdani MM, Juurlink DN. Sex differences in dose escalation and overdose death during chronic opioid therapy: a population-based cohort study. PLoS One. 2015;10(8): e0134550

Kaye AD, Jones MR, Kaye AM, Ripoll JG, Galan V, Beakley BD, et al. Prescription opioid abuse in chronic pain: an updated review of opioid abuse predictors and strategies to curb opioid abuse: part 1. Pain Physician. 2017;20(2S):S93-109.

Kee JR, Smith RG, Barnes CL. Recognizing and reducing the risk of opioid misuse in orthopaedic practice. J Surg Orthop Adv. 2016;25(4):238-43. 
Kim SC, Choudhry N, Franklin JM, Bykov K, Eikermann M, Lii J, et al. Patterns and predictors of persistent opioid use following hip or knee arthroplasty. Osteoarthr Cartil. 2017;25(9):1399-406.

Kodesh E, Shargal E, Kislev-Cohen R, Funk S, Dorfman L, Samuelly G, et al. Examination of the effectiveness of predictors for musculoskeletal injuries in female soldiers. J Sports Sci Med. 2015;14(3):515-21.

Kolodny A, Courtwright DT, Hwang CS, Kreiner P, Eadie JL, Clark TW, et al. The prescription opioid and heroin crisis: a public health approach to an epidemic of addiction. Annu Rev Public Health. 2015;36:559-74.

Kremers MH, Schilz SR, Van Houten HK, Herrin J, Koenig KM, Bozic KJ, Berry DJ. Trends in utilization and outcomes of hip arthroscopy in the United States between 2005 and 2013. J Arthroplasty. 2017;32(3):750-55.

Kucera KL, Marshall SW, Wolf SH, Padua DA, Cameron KL, Beutler Al. Association of injury history and incident injury in cadet basic military training. Med Sci Sports Exerc. 2016;48(6):1053-61.

Macintyre PE, Huxtable CA, Flint SLP, Dobbin MDH. Costs and consequences: a review of discharge opioid prescribing for ongoing management of acute pain. Anaesth Intensive Care. 2014;42(5):558-74.

Martell BA, O'Connor PG, Kerns RD, Becker WC, Morales KH, Kosten TR, et al. Systematic review: opioid treatment for chronic back pain: prevalence, efficacy, and association with addiction. Ann Intern Med. 2007;146(2):116-27.

Martinez V, Beloeil H, Marret E, Fletcher D, Ravaud P, Trinquart L. Non-opioid analgesics in adults after major surgery: systematic review with network meta-analysis of randomized trials. Br J Anaesth. 2017;118(1):22-31.

Morris BJ, Mir HR. The opioid epidemic: impact on orthopaedic surgery. J Am Acad Orthop Surg. 2015;23(5):267-71.

Mörwald EE, Olson A, Cozowicz C, Poeran J, Mazumdar M, Memtsoudis SG. Association of opioid prescription and perioperative complications in obstructive sleep apnea patients undergoing total joint arthroplasties. Sleep Breath. 2018;22(1):115-21.

Muller S, Bedson J, Mallen CD. The association between pain intensity and the prescription of analgesics and non-steroidal anti-inflammatory drugs. Eur J Pain. 2012;16(7):1014-20.

Ndlovu M, Bedson J, Jones PW, Jordan KP. Pain medication management of musculoskeletal conditions at first presentation in primary care: analysis of routinely collected medical record data. BMC Musculoskelet Disord. 2014; $15: 418$

Nuckols TK, Anderson L, Popescu I, Diamant AL, Doyle B, Di Capua P, et al. Opioid prescribing: a systematic review and critical appraisal of guidelines for chronic pain. Ann Intern Med. 2014;160(1):38-47.

Office of the Deputy Assistant Secretary of Defense for Military Community and Family Policy (ODASD (MC\&FP)). Profile of the Military Community: 2015 Demographics [Internet]: Department of Defense; 2015. Available from: http://download.militaryonesource.mil/12038/MOS/Reports/2015Demographics-Report.pdf. Accessed 14 Jan 2018.

Ramirez S, Bebarta VS, Varney SM, Ganem V, Zarzabal LA, Potter JS. Misuse of prescribed pain medication in a military population-a self-reported survey to assess a correlation with age, deployment, combat illnesses, or injury? Am J Ther. 2017;24(2):e150-6.

Rhon DI, Clewley D, Young JL, Sissel CD, Cook CE. Leveraging healthcare utilization to explore outcomes from musculoskeletal disorders: methodology for defining relevant variables from a health services data repository. BMC Med Inform Decis Mak. 2018;18(1):10.

Roy TC, Ritland BM, Sharp MA. A description of injuries in men and women while serving in Afghanistan. Mil Med. 2015;180(2):126-31.

Schoenfeld AJ, Nwosu K, Jiang W, Yau AL, Chaudhary MA, Scully RE, et al. Risk factors for prolonged opioid use following spine surgery, and the association with surgical intensity, among opioid-naive patients. J Bone Joint Surg Am. 2017;99(15):1247-52.

Shen J, Gao S. A solution to separation and multicollinearity in multiple logistic regression. J Data Sci. 2008;6(4):515-31.

Sing DC, Barry JJ, Cheah JW, Vail TP, Hansen EN. Long-acting opioid use independently predicts perioperative complication in total joint arthroplasty. J Arthroplast. 2016;31(9 Suppl):170-4.e1.

Sites BD, Harrison J, Herrick MD, Masaracchia MM, Beach ML, Davis MA. Prescription opioid use and satisfaction with care among adults with musculoskeletal conditions. Ann Fam Med. 2018;16(1):6-13.

Skala K, Reichl L, llias W, Likar R, Grogl-Aringer G, Wallner C, et al. Can we predict addiction to opioid analgesics? A possible tool to estimate the risk of opioid addiction in patients with pain. Pain Physician. 2013;16(6):593-601.
Thackeray A, Hess R, Dorius J, Brodke D, Fritz J. Relationship of opioid prescriptions to physical therapy referral and participation for Medicaid patients with new-onset low back pain. J Am Board Fam Med. 2017;30(6): 784-94.

Thomas DD, Bernhardson AS, Bernstein E, Dewing CB. Hip arthroscopy for femoroacetabular impingement in a military population. Am J Sports Med. 2017; 1:363546517726984

Unger A, Jung E, Winklbaur B, Fischer G. Gender issues in the pharmacotherapy of opioid-addicted women: buprenorphine. J Addict Dis. 2010;29(2):217-30.

Vivolo-Kantor AM, Seth P, Gladden RM, Mattson CL, Baldwin GT, Kite-Powell A, et al. Vital signs: trends in emergency department visits for suspected opioid overdoses - United States, July 2016-September 2017. MMWR Morb Mortal Wkly Rep. 2018;67(9):279-85.

Vowles KE, McEntee ML, Julnes PS, Frohe T, Ney JP, van der Goes DN. Rates of opioid misuse, abuse, and addiction in chronic pain: a systematic review and data synthesis. Pain. 2015;156(4):569-76.

Walid MS, Hyer L, Ajjan M, Barth ACM, Robinson JS Jr. Prevalence of opioid dependence in spine surgery patients and correlation with length of stay. J Opioid Manag. 2007;3(3):127-8 130-2.

Weimer MB, Hartung DM, Ahmed S, Nicolaidis C. A chronic opioid therapy dose reduction policy in primary care. Subst Abus. 2016;37(1):141-7.

White PF. The role of non-opioid analgesic techniques in the management of pain after ambulatory surgery. Anesth Analg. 2002;94(3):577-85.

Yang Z, Wilsey B, Bohm M, Weyrich M, Roy K, Ritley D, et al. Defining risk of prescription opioid overdose: pharmacy shopping and overlapping prescriptions among long-term opioid users in Medicaid. J Pain. 2015;16(5): 445-53.

Zarling BJ, Yokhana SS, Herzog DT, Markel DC. Preoperative and postoperative opiate use by the arthroplasty patient. J Arthroplast. 2016;31(10):2081-4.

Zywiel MG, Stroh DA, Lee SY, Bonutti PM, Mont MA. Chronic opioid use prior to total knee arthroplasty. J Bone Joint Surg Am. 2011;93(21):1988-93.

\section{Ready to submit your research? Choose BMC and benefit from:}

- fast, convenient online submission

- thorough peer review by experienced researchers in your field

- rapid publication on acceptance

- support for research data, including large and complex data types

- gold Open Access which fosters wider collaboration and increased citations

- maximum visibility for your research: over $100 \mathrm{M}$ website views per year

At BMC, research is always in progress.

Learn more biomedcentral.com/submissions 